\title{
APLIKASI KAIDAH KEBAHASAAN BAHASA INDONESIA DALAM TAJUK BERITA SURAT KABAR SEBAGAI KONSUMSI INFORMASI PUBLIK DI KOTA MAKASSAR
}

\author{
Juanda $^{1}$, Azis $^{2}$ \\ Universitas Negeri Makassar, Makassar \\ juanda@unm.ac.id ${ }^{1}$ azis@unm.ac.id ${ }^{2}$
}

\begin{abstract}
The purpose of this research is to determine the use of Indonesian standard in headline news in newspaper discourse relate to the diction/vocabulary; writing; sentence structure; and use of vernacular languages, and foreign terms. This research focuses on the use of Indonesian standard in the headline newspaper of Harian Fajar newspaper. This research is a qualitative method of content analysis. The source data are from daily Harian Fajar Tajuk Newspaper. The result showed that the diction or vocabulary in the discourse of headline news used language hyperbole, oxymoron, and personification. The writing word such as acronyms, technical terms. The majority of the style of language used by the writer is hyperbole. The writer used many acronyms. The technical terms are dominated by English vocabulary. The writing is not appropriate, namely: the writing of the word, the error in the writing of letters, capital letters, the compound word, and preposition di. Particle that often arise in the writing errors is pun. These of punctuation is not appropriate, namely the use of comma, in the details of words and the use of hyphen in the decoding in the words. The sentence structure in the form of the head line news of Harian Fajar is to be a symbol (+), proverbs, advice, and imperative sentence. The ambiguous sentence, conjunction occur due to improving is not appropriate, ie: untuk kemudian, padahal agar, mesti, sehingga, jadi, karena, disebabkan oleh, dan bahwa. Many sentences found in the data are ineffective. One of the reasons is became of a combination of the two ideas in a sentence. There is a tendency of the writer to write down his words affix mewriter the based words only and many sentences do not have clear subject.
\end{abstract}

Keywords: discourse, Editorial, Indonesian Standard

\section{Pendahuluan}

Bahasa sebagai alat

komunikasi merupakan sarana

yang utama dalam berinteraksi.

Pemahaman berbagai aspek

komunikasi harus dilengkapi dengan

pemahaman budaya tempat tuturan

tersebut berlangsung (Juanda, 2010;

Juanda dan Azis, 2018). Media merupakan alat menyampaikan berita, penilaian, gambaran umum berbagai hal yang berperan membentuk opini publik. Oleh karena itu, masyarakat berhak mendapatkan informasi sesuai dengan fakta serta berhak mendapatkan siaran mendidik (http://seputar 
penyiaran.Blogspot.com, 21 Maret

2011). Informasi dari media dapat diperoleh secara maksimal bilamana penutur menggunakan bahasa Indonesia yang baku bukan menggunakan bahasa sehari-hari oleh (Juanda, 2012) diistilahkan bahasa prokem. Telah banyak penelitian yang dilakukan mengenai bahasa dalam media, antara lain: Subiyakto (2000), Nuryati (2003), Adinda (2010), Syeku (2009), Siregar (2010), Nooryani (2010), Masaginting (2010), dan Widyastuti (2010). Namun, semua penelitian tersebut belum memfokuskan pada wacana Tajuk di media yang ada di Sulawesi Selatan, khususnya di Kota Makassar.

Penelitian media dengan analisis isi dilakukan (Subyakto, 2000; Nuryadi, 2003) berkenaan dengan Objetivitas Pers Nasional. Hasil penelitian pada Koran Media Indonesia, Kompas, Suara Pembaharuan, dan Suara Merdeka, cenderung objektif daripada surat kabar lain terhadap keakurasian, ketidakberpihakan kepada pihak tertentu dan validitas narasumber. Adinda (2008) menemukan campur kode pada pemberitaan remaja. Penelitian "Pemakaian Pronomina Interminativa Bahasa Indonesia dalam Harian Fajar, oleh (Syekhu, 2009) ruang lingkupnya sangat terbatas sehingga mengurangi kedalaman penelitian. Penelitian yang dilakukan (Siregar, 2010). Hasil penelitian ini mengungkapkan bahwa banyak mahasiswa berpendapat mengenai aksi-aksi yang dilakukan melalui pemberitaan di televisi yang tidak baik dan anarkis. Ada asumsi yang mengatakan bahwa pemberitaan yang anarkis menarik perhatian pemirsa. Penelitian (Nooryani, 2010) menemukan empat proses morfofonemik dalam surat kabar, yaitu: penambahan, penghilangan, penggantian, dan pergeseran. Hal ini karena pengaruh bahasa daerah. Hasil penelitian (Masaginting, 2010). adalah bahasa surat kabar pada masa Orde Baru, prareformasi berbeda. Penelitian bahasa Indonesia dalam Tajuk Rencana Surat Kabar di Medan 
Jurnal Ilmu Budaya, Vol. 16, No. 1 Agustus Tahun 2019

oleh (Widyastuti, 2010)

menguraikan kekurangcermatan

redaktur menerapkan kaidah

bahasa Indonesia.

Dari berbagai kajian atau penelitian mengenai wacana pemberitaan media massa, penulis belum menemukan kajian wacana Tajuk Fajar dengan metode analisis konten yang fokus kajiannya diksi, ketidakbakuan penggunaan bahasa Indonesia karena penggunaan bahasa Inggris, istilah asing dan bahasa daerah. Fokus perhatian penelitian ini didasarkan pada benar tidaknya bahasa secara gramatikal.

Tujuan penelitian ini untuk mengetahui penggunaan bahasa Indonesia baku dalam wacana Tajuk Fajar sebagai berikut: 1). Diksi/kosa kata pada tajuk Fajar; 2) Penulisan EYD pada tajuk Fajar; 3. Struktur kalimat pada tajuk Fajar; 4) Penggunaan bahasa daerah, bahasa Inggris, bahasa Indonesia dengan mencampuradukkan struktur bahasa; istilah asing yang sudah diindonesiakan.
Tajuk merupakan wacana. Wacana merujuk pada bahasa percakapan, cara berbicara, (van Dijk, 2001: 1). Wacana merujuk pada bentuk penggunaan bahasa, tuturan publik (Schiffrin, 1994: 24). Analisis wacana kritis oleh (Fairclough, 1995), yaitu wacana sebagai teks: wacana sebagai praktik discursive (wacana sebagai produksi, diciptakan sebagai sirkulasi, dan konsumsi masyarakat); dan wacana sebagai praktik sosial. Wacana sebagai teks, yaitu ciri-ciri linguistik yang disusun secara nyata dalam wacana; diksi, kosa kata, tata bahasa, kohesi, dan struktur teks (Blommaert, 2005: 44). Kajian wacana dalam aspek ini menekankan pada penggunaan bahasa, tinjauan dari segi linguistik deskriptif. Hal ini berbeda dengan kajian yang mengabaikan aspek linguistik tetapi kajian pada bahasa dalam interaksi sosial (Jorgensen, dan Louis J.Philips, 2007: 118). Di sisi lain kajian wacana memfokuskan pada aspek linguistik yang 
Jurnal Ilmu Budaya, Vol. 16, No. 1 Agustus Tahun 2019

digunakan dalam teks (Scollon and

Suzanne Wong Scollon, 2001: 538).

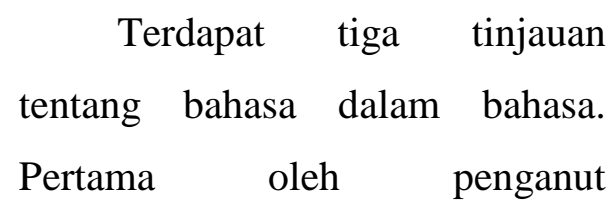

positivisme-empiris. Paham ini berpendapat analisis wacana menggambarkan tata aturan, kalimat. Pandangan kedua, kontruktivisme. Analisis wacana yang mengkaji tujuan tertentu yang tersembunyi dalam subjek yang mengemukakan suatu pernyataan, analisis

framing/bingkai. Pandangan ketiga adalah wacana kritis, menekankan konstelasi yang terjadi pada proses produksi dan reproduksi makna wacana yang dipakai mengungkap pemberitaan dengan penguasa (Fairclough, 1999: 10-11; Eriyanto, 2001). Analisis isi sebagai suatu teknik penelitian yang objektif, sistematik, dan penjelasan kuantitatif yang jelas dalam komunikasi isi. Analisis isi termasuk pengklasifikasian, tabulasi kesalahan grammar, ejaan dalam penyampaian informasi
(Gall, Joyce P.Gall, dan Walter R.

Borg; 2003: 278).

Buku tatabahasa merupakan kumpulan kaidah tatabahasa yang kepadanannya bergantung pada taraf kecermatan dan kecanggihan 'sophistication' penyusunannya (Moeliono, 1985: 27-29). Menurut (Fowley dan Robert van Valin, 1984:27-29) bahasa adalah sistem tanda dengan kaidah-kaidah penggabungannya. Pemahaman kaidah tatabahasa, kompetensi dan penggunaannya, performansi (Chomsky, 1965) perlu diterapkan di media massa bagi para penulis berita.

Pemakaian bahasa (Widdowson, 1978) menggunakan istilah usage dan use. Usage berupa kemampuan penyusunan kalimat yang gramatikal. Use adalah kemampuan menggunakan kaidah-kaidah kebahasaan secara efektif. Kemampuan berbahasa yang meliputi membaca dan menulis perlu dikembangkan (Akhadiah, 1994: 1). Pembelajaran Bahasa Indonesia untuk meningkatkan keterampilan siswa 
Jurnal Ilmu Budaya, Vol. 16, No. 1 Agustus Tahun 2019

berkomunikasi (Ahmad, 2003:

dan ungkapan (Keraf, 2008: 23).

110).

Ragam bahasa yang dipakai dalam media massa adalah ragam baku yang sesuai dengan kaidah tatabahasa Indonesia (Soeparno, 2003). Penulis harus memperhatikan makna dan aspekaspek nilai yang membangun makna itu, aktivitas, politik, keterkaitan dan semiotik (Gee, 2001). Beberapa ciri kebakuan (B) dan ketidakbakuan (TB) BI di antaranya: penggunaan awalan ber- dan me- secara eksplisit; Penggunaan unsur-unsur gramatikal yang tidak redundan; Pengguaan bentuk gramatik yang tidak dipendekkan. Selain faktor kebakuan, kalimat yang digunakan dalam media massa seharusnya memiliki ciri-ciri kalimat efektif; bentuk gramatik yang tidak bermakna ganda (Suroso, 2007: 217).

Paragraf sebaiknya tidak berisi sebuah kalimat atau dua buah kalimat saja. Pilihan kata untuk menyatakan suatu ide seperti fraseologi, gaya bahasa, Gaya bahasa mencakup diksi atau pilihan leksikal, struktur kalimat (Sobur, 2006: 82; Wahid dan Juanda, 2006). Tata bahasa dan leksikon, kosakata merupakan fenomena dalam bahasa, penggunaan kata memengaruhi tatabahasa (Willis, 2004: 83). Fishman (1972: mengemukakan faktor utama perubahan bahasa dalam masyarakat modern, yaitu: Pengadopsian bahasa daerah atau asing untuk keperluan pemerintah, nasional; Perkembangan teknologi, pendidikan; budaya; dan Pemindahan bahasa yang diimpor oleh bahasa asli misalnya kasus di Benua Asia dan Afrika.

Tujuan penelitian ini untuk mengetahui penggunaan bahasa Indonesia baku dalam wacana Tajuk Fajar yang berkaitan dengan diksi/kosa kata; kaidah penulisan; struktur kalimat; dan penggunaan bahasa daerah, bahasa Indonesia dengan istilah asing. Penelitian ini memfokuskan kajiannya pada 
Jurnal Ilmu Budaya, Vol. 16, No. 1 Agustus Tahun 2019

penggunaan bahasa Indonesia

Mayor, 2010: 126). Analisis data

baku Tajuk harian Fajar.

dilakukan pada saat proses

penelitian berlangsung hingga

\section{Metode Penelitian}

Jenis penelitian ini adalah kualitatif dengan menggunakan metode deskriptif. Data dianalisis dengan menggunakan pendekatan analisis isi. Data dari berbagai bentuk dan sumber, antara lain dari materi, benda, bacaan (Darlington and Arthur Henry Acott, 2002: 142). Penelitian ini sumber datanya dari harian Fajar mulai tanggal 1 April s.d. 1 Mei 2015. Penelitian ini merupakan penelitian kepustakaan, dokumen, tajuk pada harian Fajar. Data dikumpulkan setiap hari sesuai dengan penerbitan berita harian Fajar. Tahap pertama dalam analisis adalah identifikasi sub-sub kajian, membaca dan membaca ulang untuk mendeskripsikan dan menemukan kata-kata yang mendukung dalam penelitian. Kredibilitas didasarkan pada kejelasan data; kredibel dalam konteks; data yang tidak didukung dengan fakta (Baden and C.h. selesai (Merriam, 2002: 209). Analisis meliputi pemilahan dan penyusunan data, pengelompokan dalam unit-unit, sintesis dan penemuan pola-pola (Bogdan and Sari Knopp Biklein, 2007: 159).

\section{Hasil Penelitian dan Pembahasan}

Penggunaan bahasa Indonesia yang baku, baik dan benar pada tajuk dalam koran Fajar di Kota Makassar belum maksimal dengan ketidaktepatan pemilihan diksi, kosa kata, penggunaan istilah asing, daerah, struktur kalimat, dan penulisan EYD. Secara rinci dapat dilihat dalam uraian di bawah ini.

\section{Diksi/Pemilihan Kosa Kata.}

Diksi yang lebih berkaitan pada penggunaan gaya bahasa pada wartawan adalah yang ditemukan pada judul wacana tajuk, yaitu penggunaan gaya bahasa hiperbola, oksimoron, dan personifikasi. Penulisan kata 
berupa akronim, istilah teknis. Jenis diksi dan contohnya dapat dilihat di bawah ini.

\section{a. Hiperbola}

Penggunaan gaya bahasa hiperbola ditemukan pada judul wacana tajuk, contoh:

Nasib Bangsa di Tangan Guru

(Fajar, 1 April 2015).

Pernyataan ini dibesar-besarkan padahal nasib bangsa Indonesia ini ditentukan oleh berbagai elemen, yaitu: masyarakat dan pemerintah

\section{b. Oksimoron}

Maju mundur keputusan presiden (Fajar, 7 April 2015).

Kata maju dan mundur digunakan secara bersama, dipertentangkan. Majas Oksimoron: mengandung pertentangan terhadap kata-kata berlawanan dijadikan paradoks.

\section{c. Personifikasi}

Makassar pernah mengalami kehancuran ketika VOC mencengkeramkan kuku (Fajar, 9 April 2015).

VOC sebagai persekutuan dagang Belanda, merupakan benda mati disandingkan dengan kata mencengkeramkan kuku seperti mahluk hidup, bentuk gaya bahasa ini menghidup-hidupkan benda mati atau penginsanan. Maksud kalimat di atas yaitu VOC pernah memonopoli perdagangan di Makassar.

d. Akronim

Optimisme baru periode kedua sayang.

Kata sayang merupakan penggabungan dari dua nama yang merujuk pada gubernur dan wakilnya. Gunbernur Provinsi Sulawesi Selatan, Syahrul Yasin Limpo dan wakilnya, Arifin Nu'mang.

e. Istilah Teknis

Penggunaan istilah teknis menjadikan pembaca yang awam mengenai istilah di bidang POLRI, perekonomian, dan seni kesulitan memahami makna istilah tersebut. Contoh berikut ini.

1) Usaha Polri sejauh ini telah berhasil menangkap dan menembak mati sejumlah anggota kelompok Santoso yang alibinya selalu berpindah-pindah. Kelompok Santoso sudah 
membentuk pasukan kombat untuk siap memerangi pasukan ... (Fajar, 4 April 2015).

Kata Alibi merupakan istilah teknis di bidang POLRI yang artinya "Bukti bahwa seseorang berada di tempat lain ketika peristiwa pidana terjadi, tidak berada di tempat kejadian." Pasukan kombat artinya pertempuran, persaingan, perebutan, antar perseorangan atau antarkelompok. Kartel merupakan istilah teknis di bidang ekonomi artinya organisasi perusahaan besar, negara yang memproduksi barang sejenis. kata alibi, pasukan kombat, dan kartel merupakan istilah teknis yang sulit dipahami oleh pembaca.

2) Kartini adalah potret wanita yang futuristik, tertuju masa depan, modern (Fajar, 21 April 2015).

Kata futuristik berasal dari bahasa Prancis, futur atau bahasa Inggris future yang keduanya berarti "masa depan" orang yang percaya masa mendatang lebih baik, modern, dan lebih konkrit.

\section{Penulisan EYD}

Penulisan EYD yang tidak tepat, yaitu: Penulisan kata, penulisan huruf kapital, preposisi, dan partikel. Penggunaan tanda baca yang tidak tepat, yaitu pada pemakaian tanda koma dalam rincian kata dan penggunaan tanda penghubung dalam pemenggalan kata. Penulisan kata terdapat kekeliruan dalam penulisan abjad atau penulisan huruf dan penulisan gabungan kata.

a. Kata

poliri $\longrightarrow$ polisi (Fajar, 4 April 2015)

terbellenggu $\rightarrow$ terbelenggu

(Fajar, 4 April 2015).

b. Huruf Kapital

Dititik inilah terkadang sulit dilakoni kaum Hawa dengan sempurna hanya karena giuran posisi, peluang, ataupun prestise di ruang-ruang public (Fajar, 21April 2015).

Penulisan huruf kapital pada kalimat di atas khususnya pada kata kaum Hawa merupakan nama jenis sehingga penulisannya seharusnya huruf kecil, kaum hawa.

c. Preposisi 
Penggunaan preposisi di dalam data, penulisannya dirangkaikan dengan kata yang menyertainya padahal seharusnya dipisahkan.

\section{Contoh:}

Namun, terjadi perlambatan disektor perbankan yaitu pada masalah melemahnya angka pertumbuhan kredit modal kerja (Fajar, 11 Mei 2015).

seharusnya

Namun, terjadi perlambatan di sektor perbankan yaitu pada masalah melemahnya angka pertumbuhan kredit modal kerja.

d. Partikel

Penulisan partikel pun yang berfungsi sebagai penegasan dipisahkan dengan kata dasar.

Tepatpun seharusnya tepat pun.

e. Pemakaian Tanda Baca

Pemakaian tanda baca yang ditemukan dalam data, yaitu tanda hubung (-) dan tanda koma (,)

1) Tanda Hubung (-)

Penggunaan tanda penghubung yang tidak tepat banyak ditemukan pada pemenggalan kata.

menggar - seharusnya menggais bawahi risbawahi penyada- seharusnya penyadaran -an men-transparan-kan (Fajar, 6 April 2015).

2) Tanda Koma (,)

Penulisan tanda koma yang tidak tepat penggunaannya ditemukan dalam kalimat yang berupa rincian. Contoh berikut ini.

Selain karena perubahan struktural, Indonesia tentu diuntungkan oleh sentimen negatif investasi di negara-negara favorit seperti Malaysia, Thailand dan Tiongkok (Fajar, 6 April 2015).

\section{Seharusnya,}

Selain karena perubahan struktural, Indonesia tentu diuntungkan oleh sentimen negatif investasi di negara-negara favorit seperti Malaysia, Thailand, dan Tiongkok.

\section{Kalimat}

Kalimat pada tajuk Fajar berbentuk penggunaan kalimat yang menggunakan symbol (+), peribahasa, nasihat, dan kalimat perintah, contoh berikut ini.

a. Penggunaan Simbol

Makassar + baik (Fajar, 8 Mei 2015).

Maksud simbol + (tambah, bertambah). Jadi, pernyataan di atas adalah "Makassar bertambah baik."

b. Peribahasa 
1). Sambil Menyelam minum air (Fajar, 4 April 2015).

2). Kejahatan dalam proses pendidikan seperti bocornya materi UN yang dikerjakan menyuguhkan kenyataan dalam ungkapan "Pagar makan tanaman" (Fajar, 18 April).

c. Nasihat

Nasihat dalam wacana tajuk

Fajar ditemukan dalam satu judul tajuk, yaitu:

Tak perlu malu belajar ke Siprus (Fajar, 15 April 2015).

\section{d. Kalimat Perintah}

Jangan habiskan energi untuk sepak bola (Fajar, 22 April 2015).

e. Kalimat Efektif

Banyak kalimat yang ditemukan dalam data tidak efektif, seperti di bawah ini.

\section{Penggunaan Konjungsi}

Kalimat rancu dalam data terjadi karena penempatan konjungsi yang tidak tepat. Penggunaan kata penghubung yang tidak tepat, yaitu: untuk kemudian, padahal agar, mesti, sehingga, jadi, karena, disebabkan karena, bahwa.

Konjungsi yang digunakan berlebihan, penggunaan dua konjungsi yang disandingkan atau digabungkan dalam sebuah kalimat. Ada kecenderungan menggabungkan dua konjungsi. Selain itu, cenderung menggunakan konjungsi dalam suatu kalimat yang seharusnya tidak digunakan, sebetulnya. Penggunaan kata tersebut dapat dilihat dalam data di bawah ini:

a) Potensi desa cukup besar sebab menjadi awal berdirinya sebuah wilayah untuk kemudian tumbuh dan berkembang (Fajar, 3 April 2015).

Seharusnya,

Potensi desa cukup besar sebab awal berdirinya sebuah wilayah yang tumbuh dan berkembang.

b) Padahal, agar tercipta keseimbangan, mesti dilakukan percepatan pembangunan pedesaan (Fajar, 3 April 2015).

Seharusnya,

Agar tercipta keseimbangan pertumbuhan antara desa dan kota, mesti dilakukan percepatan pembangunan pedesaan.

Seharusnya,

Saat konflik di tubuh sepak bola nasional tengah mendekati titik tertinggi, para pengambil kebijakan, sponsor, dan publik nasional harus merenung dalamdalam (Fajar, 22 April 2015). 
Penggunaan kata sehingga yang tidak tepat pada kalimat di atas dan penggunaan kata yang secara berlebihan. Contoh kalimat berikut ini. Demikian yang layak bagi juga insentif yang layak bagi komoditas ...

Seharusnya,

Penguatan pembangunan pedesaan akan memberikan harapan bagi masyarakat dan memberi kesempatan untuk regenerasi petani seperti insentif yang layak bagi komoditas hasil pertanian serta membebaskan pasar komoditas kebutuhan pangan dari praktik kartel dan mafia (Fajar, 6 April 2015).

Kartel; perusahaan besar atau organisasi, yang memproduksi barang sejenis; persetujuan kelompok dalam pengendalian harga komuditas tertentu.

\section{Kesatuan Gagasan}

Kalimat yang efektif harus memiliki kesatuan gagasan. Selain itu kalimat efektif harus memiliki sekurang-kurang subjek dan predikat.

Contoh berikut ini.

1). Minimal, jika tak ketemu, daya "deterring" kehadiran TNI yang sedang berlatihan dapat memberi signal bagi mereka untuk memilih menyerahkan diri atau tetap menjadi buron ( Fajar, 4 April 2015).

Deterring 'menghalangi'; penggunaan kata minimal tidak tepat; diganti kata sebaliknya;

Sebaliknya, jika tidak bertemu, daya "deterring" kehadiran TNI yang sedang berlatihan dapat memberi signal bagi mereka untuk memilih menyerahkan diri atau tetap menjadi buron.

2). Baik secara politis maupun sosialitas "keseiringan" pemerintah Kota Makassar dengan Pemerintah Provinsi Sulsel, patut diapresiasi agar program-program pembangunan juga berjalan seiring. Tidak tumpang tindih atau malah saling bongkar atau juga bahkan saling menyalahkan. Yang lebih parah jika saling apatis (Fajar, 9 April 2015).

Pembangunan tidak.....

Tidak ada subjek kalimat; program pembangunan; penggunaan kata yang seharusnya diganti kata dan, dan pengurutan secara logis

Seharusnya,

Baik secara politis maupun sosialitas "keseiringan" pemerintah Kota Makassar dengan Pemerintah Provinsi Sulsel patut diapresiasi agar programprogram pembangunan juga berjalan seiring dengan tidak tumpang tindih, saling 
menyalahkan, saling bongkar dan saling apatis.

\section{Penggunaan Awalan}

Berdasarkan data ada kecenderungan penulis pada kata yang berawalan menuliskan kata dasarnya saja. Contoh di bawah ini.

1) Buku bacaan umum termasuk cerita rekaan, buku pengetahuan umum, buku tentang pengetahuan ... yang seharusnya giat dan rajin baca (Fajar, 25 April 2015).

\section{Seharusnya}

Buku bacaan umum termasuk cerita rekaan, buku pengetahuan umum, buku tentang pengetahuan ...yang seharusnya giat dan rajin membaca (Fajar, 25 April 2015).

2) Bukti kurangnya minat baca jika dibandingkan dengan minat nonton sambil mendengar bisa diamati ketika running text di televisi (Fajar, 25 April).

\section{Seharusnya}

Bukti kurangnya minat membaca jika dibandingkan dengan minat menonton sambil mendengar bisa diamati ketika running text di televisi (Fajar, 25 April).

\section{Penggunaan Bahasa \\ Daerah dan Istilah Asing.}

a. Penggunaan Istilah daerah: simsalabin, se-lebay, tok

1) Kita tidak ingin ada status sim salabin, terutama bagi terpidana kasus narkoba (Fajar, 28 April 2015).

2) Nota keberatan tetap dikirimkan, tapi tidak 'se-lebay' Australia dan Prancis saat ini (Fajar, 29 April 2015).

Lebay ' berlebihan'

3) Kita sejatinya tidak mengulangulang peringatan Hari Kartini di sekitar kebaya tok saja melainkan mengedepankan prestasi alias unjuk kebolehan (Fajar, 21 April 2015).

Penggunaan kata tok yang merupakan istilah daerah sebenarnya sudah direpresentasikan oleh kata saja.

\section{b. Istilah Asing}

Istilah asing berupa kosa kata yang ditemukan dalam data, yaitu kosa kata sebagai berikut: military civil service, Liquid Petroleum Gas, Maccini Sombala of Indonesia, Tagline, t.line, new port, bus rapid transit, Bypass, new port, underpressure, to be or not to be, estate, moral and celestial virtues, pseudo-bonum, moralachiement. 
c. Penggabungan antara Istilah Indonesia dengan Asing

Kesediaan SBY untuk memimpin kembali Partai Demokrat, merupakan lambang ekstra hatihati' prudent' (Fajar, 12 Mei 2015).

Diksi yang lebih berkaitan pada penggunaan gaya bahasa pada wartawan adalah yang ditemukan pada judul wacana tajuk, yaitu penggunaan gaya bahasa hiperbola, oksimoron, dan personifikasi. Penulisan kata berupa akronim, istilah teknis. Ada kecenderungan wartawan membesar-besarkan suatu kejadian atau peristiwa dengan menggunakan majas hiperbola, mempertentangkan dua hal dalah suatu kelompok kata atau frasa. Gaya bahasa ini juga mendominasi pemakaiannya dalam iklan-iklan di televisi seperti penelitian (Budiyanto, 2014; Salam, 2010: 271) tentang aspek persuasif dalam bahasa iklan partai politik. Selain itu, ditemukan penggunaan majas personifikasi, yaitu penginsanan terhadap suatu benda. Akronim berasal dari sebuah bentuk panjang lebih sedikit dua kata dan lebih banyak tujuh kata tanpa penyisipan konjungsi di dalamnya (Putri, 2015). Penggunaaan akronim yang sering muncul dalam penulisan "Tajuk" dan istilah teknis. Hal ini dilakukan guna efesiensi penulisan karena keterbatasan ruang dalam penulisan "Tajuk." Istilah teknis sering muncul dalam berbagai edisi yang menyulitkan pembaca memahami kosa kata tersebut. Hal ini merupakan suatu kecenderungan penggunaan istilah yang lebih mutakhir sehingga menambah kosa kata BI. Istilah tersebut belum memasyarakat penggunaannya.

Penulisan EYD yang tidak tepat, yaitu: Penulisan kata, penulisan preposisi di, yaitu bentuk yang memiliki juga fungsi sebagai awalan merupakan bentuk yang memiliki frekuensi kesalahan yang dominan. Partikel yang sering muncul kesalahan penulisannya adalah pun karena selalu dirangkaikan dengan kata dasar. Hal ini sejalan dengan 
Fishman (1972: 112) dan menyambung dua klausa yang

(Widyastuti, 2010).

Kalimat pada tajuk Fajar berbentuk penggunaan kalimat yang menggunakan symbol (+), peribahasa, nasihat, dan kalimat perintah. Kalimat rancu terjadi karena penempatan konjungsi yang tidak tepat. Penggunaan kata penghubung yang tidak tepat, yaitu: untuk kemudian, padahal agar, mesti, sehingga, jadi, karena, disebabkan oleh, bahwa. Konjungsi yang digunakan berlebihan, penggunaan dua konjungsi yang disandingkan atau digabungkan dalam sebuah kalimat. Ada kecenderungan menggabungkan dua konjungsi. Selain itu, cenderung menggunakan konjungsi dalam suatu kalimat yang seharusnya tidak digunakan. Kekeliruan penggunaan konjungsi dalam kalimat sering pula ditemukan dalam penulisan akademik di kalangan mahasiswa, penelitian (Azis dan Juanda, 2017) kesalahan penggunaan konjungsi seperti konjungsi adversative yang menyatakan kontras: tetapi, namun; konjungsi intra kalimat: agar dan sehingga: konjungsi kausal, karena atau sebab, disebabkan oleh; konjungsi subordinatif: meskipun, kalau, dan bahwa.

Banyak kalimat yang ditemukan dalam data tidak efektif. Salah satu penyebabnya adalah penggabungan dua gagasan dalam sebuah kalimat. Penulis tidak menguasai aspek-aspek kaidah-kaidah sintaksis bahasa itu secara aktif dan tingkat penalaran atau logika yang tepat (Keraf, 1989: 35). Ada kecenderungan penulis pada kata yang berawalan me- menuliskan kata dasarnya saja. Banyak kalimat yang tidak jelas subjeknya. Hal ini menjadikan pembaca membuat penafsiran yang tidak tepat terhadap kalimat tersebut.

Penggunaan Istilah daerah: simsalabin, se-lebay, tok. Kosa kata bahasa Bugis 'tok' ditemukan penggunaannya dalam wacana tajuk yang seharusnya digantikan 
kosa kata bahasa Indonesia dengan kata saja. Istilah asing ini didominasi dari bahasa Inggris. LPG 'Liquid Petroleum Gas.'

Glos kosa kata yang tidak diindonesiakan dapat dilihat sebagai berikut: line ' klimaks, bagian puncak, new port 'pelabuhan baru', bus rapid transit, 'bus sistem pengangkutan cepat', dan pembangunan Bypass Mamminasata 'jalan raya dipinggir kota untuk daerah ramai,' underpressure, to be or not to be, 'menjadi atau tidak menjadi, estate 'tanah',moral and celestial, 'yang berhubungan dengan angkasa, sorga, 'virtues 'kebaikan,' 'moral achievement, prestasi' 'nilai-nilai moral yang sahih. Penggunaan istilah asing ini ada beberapa yang disandingkan dengan padanannya bahasa Indonesia, yaitu: hukum tetap 'inkracht,' ditekan, 'underpressure,' bermuatan nilainilai keutamaan 'moral and celestial virtues,' nama baik semu 'pseudo-. Sebagian besar kosa kata berbahasa Inggris tidak diindonesiakan sehingga menyulitkan

pembaca memahaminya, terutama pembaca awam yang mendominasi dalam membaca tajuk tersebut.

Ragam bahasa yang digunakan dalam wacana tajuk Fajar banyak yang tidak baku. Ragam bahasa yang dipakai dalam media massa seharusnya ragam baku (Soeparno, 2003).

Penggabungan antara Istilah Indonesia dengan Asing, yaitu ekstra hati-hati ' prudent.' Penelitian (Nooryani, 2010) Menemukan empat proses morfofonemik dalam surat kabar yaitu: penambahan, penghilangan, penggantian, dan pergeseran. Hal ini karena pengaruh bahasa daerah.

\section{Penutup}

Diksi atau pemilihan kosa kata dalam wacana Tajuk Fajar banyak menggunakan gaya bahasa hiperbola, oksimoron, dan personifikasi. Penulisan kata berupa akronim, istilah teknis. Mayoritas gaya bahasa yang digunakan penulis adalah hiperbola. Penulis banyak 
Jurnal Ilmu Budaya, Vol. 16, No. 1 Agustus Tahun 2019

menggunakan akronim baru. penggabungan dua gagasan dalam

Istilah teknis masih didominasi

sebuah kalimat.

Ada

oleh kosa kata bahasa asing.

Penulisan EYD yang tidak kecenderungan penulis pada kata yang berawalan me- menuliskan tepat, yaitu: Penulisan kata, yaitu kata dasarnya saja. Banyak kalimat kesalahan dalam penulisan huruf, penulisan huruf kapital dan yang tidak jelas subjeknya.

Penggunaan Istilah daerah: penulisan gabungan kata, preposisi di. Partikel yang sering muncul kesalahan penulisannya adalah pun. Penggunaan tanda baca yang tidak tepat, yaitu pada pemakaian tanda koma dalam rincian kata dan penggunaan tanda penghubung dalam pemenggalan kata.

Struktur kalimat pada tajuk Fajar berbentuk penggunaan kalimat yang menggunakan symbol (+), peribahasa, nasihat, dan kalimat perintah. Kalimat rancu terjadi karena penempatan konjungsi yang tidak tepat. Penggunaan kata penghubung yang tidak tepat, yaitu: untuk kemudian, padahal agar, mesti, sehingga, jadi, karena, disebabkan oleh, dan bahwa. Banyak kalimat yang ditemukan dalam data tidak efektif. Salah satu penyebabnya adalah simsalabin, se-lebay, tok. Kosa kata bahasa Bugis 'tok'. Istilah asing yang dominan berasal dari kosa kata bahasa Inggris. Istilah asing tersebut ada yang tidak disandingkan dengan bahasa Indonesia dan kosa kata ini mayoritas. Sementara itu ada sebagian kecil kosa kata yang disandingkan dengan bahasa Indonesia atau disertakan kosa kata Indonesianya. Selain itu, penulis wacana tajuk kadangkadang menggabungkan antara istilah Indonesia dengan istilah asing sehingga menyulitkan pembaca memahami isi pesan yang disampaikan oleh penuli.

\section{Daftar Pustaka}

Adinda. 2010. "Campur Kode dalam Surat Kabar Pontianak Post Kolom X-Presi, " http:// 
ashadique.blogspot.com., $\quad 28$

Maret 2010.

Ahmad, Kasina. 2003. "Pelaksanaan Pembelajaran Terpadu Bahasa Indonesia di Kelas 111 Sekolah Dasar." Jurnal Teknodik, E'Learning dan Aplikasinya. No. 12 Oktober 2003.

Akhadiah, Sabarti. 1994. "Pembelajaan Bahasa Indonesia di Kelas Awal AD: Sebuah Kajian Teoretis ke Arah Pembaharuan." Jakarta: Lembaga Penelitian Universitas Negeri Jakarta.

Azis, A., \& Juanda, J. 2017. Kohesi Gramatikal: Kajian Keutuhan Wacana Tugas Mahasiswa Pendidikan Bahasa Dan Sastra Indonesia, Fakultas Bahasa Dan Sastra, Universitas Negeri Makassar. Jurnal Bahasa dan seni, 45(2), 170180.

Baden, Maggi Savin and Claire Howell Major. 2010. New Approaches to Quatitative Research, Wisdom and Unceftainty. London : Routledge, Taylor and Francis Group.

Blommaert, Jan. 2005. Discourse a Critical Introduction. New York: Cambridge University Press.

Bogdan, Robert C. and Sari Knopp Biklein. 2007. Qualitatif Research for Education, an
Introduction to Theory and Methods. New York: Pearson.

Budiyanto, Dwi. 2014. “Aspek Persuasif dalam Bahasa Iklan Partai Politik." Litera, Jurnal Penelitian Bahasa, Sastra dan Pengajarannya." Vol.13No. 1, April 2014.

Chomsky, Noam. 1965. Aspect of the Theory of Syntax. Cambridge, Mass MIT Press.

Darlington, Bernard Olsson and Arthur Henry Acott. 2002. Qualitative Research in Practice; Stories From the Field. Australia: Allen \& Unwin.

Eryanto. 2001. Analisis wacana, Pengantar Analisis Teks Media. Yokyakarta: LKiS.

Fairclough, Norman. 1995. Media Discourse. London: Great Britain.

Fairclough, Norman. 1999. Critical Discourse Analysis, the Citical Study of Language. New York: Addission Wesley Longman.

Fajar. 2015. "Tajuk" Edisi April dan Mei. Makassar.

Fishman, J.A. 1972. The Sociology of Language. RowlyMassachusett: Newbury House.

Fowley, William and Robert Van Valin. 1984. Funtional Syntax 
and Universal Grammar. Cambridge University Press.

Gall, Meredith D, Joyce P.Gall, Walter R. Borg. 2003. Educational Research, An Introduction. New York: Pearson Educatin.

Gee, James Paul. 2001. An tntroduction to Discourse Analysis. London: Routledge.

Jorgensesn, Marianne W. dan Louise J. Phillips. 2007. Discourse Analisys, ' Theory and Method. Atau Analisis Wacana, Teori dan Metode, terj. Abdul Sukur lbrahim. Yokyakarta: Pustaka Pelajar.

Juanda, J. 2010. Peranan Pendidikan Formal dalam Proses Pembudayaan. Lentera Pendidikan: Jurnal Ilmu Tarbiyah dan Keguruan, 13(1), 1-15.

Juanda, J. 2012. Bahasa Prokem dan Pembelajaran Bahasa Indonesia. RETORIKA, Jurnal Bahasa, Sastra, dan Pengajarannya, 8(1), 28-36.

Juanda, J., \& Azis, A. 2018. Wacana Percakapan Mappitu Etnis Bugis Wajo Sulawesi Selatan, Indonesia Pendekatan Etnografi Komunikasi. JP-BSI (Jurnal Pendidikan Bahasa dan Sastra Indonesia), 3(2), 71-76.

Keraf, Gorys. 1989. Komposisi. Ende, Flores: Nusa Indah.
Keraf, Gorys. 2008. Diksi dan Gaya Bahasa. Jakarta: PT Gramedia utama.

Massaginting, Elia. 2010. "Analisis Surat Kabar Masa Pemerintahan Presiden Suharto, Habibie dan Gus Dur." http:/// www. Researchgate-net. Publication,diakses 20 Maret 2011.

Merriam, Sharan B. 2002. Quatitative Research in Practice, Examples for Discussion and Analysis. New York: Jossey Bass.

Moeliono, Anton. 1985. Pengembangan dan Pembinaan Bahasa, Ancangan Alternatif di dalam Perencanaan Bahasa. Jakarta: Djambatan.

Nuryadi, M. 2003. "Analisis Isi dari Informasi Lingkungan Hidup di Beberapa Surat Kabar, Studi Kasus Surat Kabar Kompas, Koran Tempo, dan Sinar Harapan." PSIL-PPS Ul Jakarta.

Noryani, Rusma. 2010. "Proses Morfofonemik dalam Surat Kabar Harian Metro Banjar. "Pendikan Bahasa dan Sastra lndonesia Lambung Mangkurat.

Putri, Rima Gustiar Nadhia. 2015. Akronim dan Bentuk Panjang dalam Susunan Organisasi dan Satuan Kerja pada Tingkat 
Markas Besar Kepolisian

Negara Republik Indonesia."

Sirok Bastra, Jurnal

Kebahasaan dan Kesastraan.

Vol.3 No.1, Juni 2015. Kantor

Bahasa Provinsi Bangka

Belitung.

Salam, Aprinus. 2010. "Bahasa Indonesia, Perubahan Sosial, dan Masa Depan Bangsa.” Humaniora, Jurnal Budaya, Sastra, dan Bahasa, FIB, UGM. Vol. 22, No.3, Oktober 2010.

Schiffrin, Deborah. 1994. Approaches to Discourse. Massachusetts: Blackwell.

Scollon, Ron and Suzanne Wong Scollon. 2001. "Discourse and Interculltural Communication," in the Hand Book of Discourse Analysis. Deborah Schriffin, Deborah Tannen, and Heidi Hamilton, Ed. Oxford: Blackwell Publisher.

Siregar, Yulika Aditya. 2010. "Pemberitaan Aksi Mahasiswa di Media Massa dan Pembentukan Opini Publik." http ://repository.usu'ac'id', diakses 28 Maret 2011.

Soeparno. 2003. Bahasa Ilmiah dalam Artikel Lokakarya Penulisan Artikel Ilmiah. FBS UNY, Yokyakarta FBS UNY.

Sobur, Alex. 2006. Analisis Teks Media. Bandung: PT Remadja Rosdakarya.
Subiakto, Henry. 2000. "Objektivitas Pemberitaan Pers Nasional Fakultas Ilmu Sosial dan Ilmu Politik Universitas Air Langga Surabaya," http;// adlnlib. Unair.ac.id., diakses 20 Maret 2011.

Suroso. 2007. "Menulis Karya Tulis Ilmiah dan Mengenal Gaya Penulisan." Jurnal Teknodik. No. 20 April 2007.

Syekhu. 2009. "Pemakaian Pronomina Interminativa Bahasa Indonesia dalam Harian Fajar," http:// jaringskripsi.wordpress.com., diakses 20 Maret 2011.

Van Dijk, Teun A. 2001. Discourse as Structure and Process: Discourse Studies A Multidisiplinary Introduction, Vol. 1. London: Sage Publication.

Wahid, S., \& Juanda. 2006. Analisis wacana. Badan penerbit Universitas Negeri Makassar (UNM).

Widdowson, H.G. 1978. Teaching Language as Communication. Oxford University Press.

Widyastitu, $\quad$ Reni. 2011. "Penggunaan Bahasa Indonesia dalam Tajuk Rencana Surat Kabar di Medan," http// www researcgate.net, diakses 25 Maret 2011. 
Jurnal Ilmu Budaya, Vol. 16, No. 1 Agustus Tahun 2019

Willis, Dave. 2004. "Grammar and Lexis some Pedagogical Implications," in Techniques of Description, Spoken, and Written Discourse. John M. Sinclair, Michael Hoey and Gwyneth Fox, Ed. London: Routledge. 